\title{
NATIONAL ANTIRETROVIRAL TREATMENT REGISTER - A NECESSITY?
}

\author{
Robin Wood, BSc, BM, DTME H, MMed, FCP (SA) \\ Linda-Gail Bekker, MB ChB, FCP (SA), DTM\& H, $P h D$ \\ HIV Research Unit, Department of Medicine, University of Cape Tozun \\ Des Martin, MB ChB, MMed, DTME H, DPH \\ University of the Witwatersrand and HIV Clinicians Society \\ Penny Penhall \\ HIV Clinicians Society
}

Highly active antiretroviral therapy (HAART) has greatly improved the prognosis of HIV-infected individuals in affluent countries, resulting in a marked drop in AIDSrelated mortality. ${ }^{1.3}$ in order to extend the benefits to resource-poor countries, the World Health Organisation (WHO) has called for expanded access to ART. ${ }^{+}$

\section{PERCEPTIONS OF SOUTHERN AFRICAN AND OTHER RESOURCE-POOR SETTINGS}

A concern that widespread, unregulated access to antiretroviral (ARV) drugs in sub-Saharan Africa could lead to the rapid emergence of resistant viral strains, spelling doom for the individual, curtailing future treatment options, and leading to transmission of resistant virus, has been voiced. This pessimistic perception of the outcome of HAART programmes in resource-poor settings is not inevitable, if a well-organised national treatment plan is developed.

Examples of highly successful ARV programmes in countries at a comparable stage of development to southern African countries, and with similar socioeconomic challenges, are the ARV (HAART) programmes incorporated into the Brazilian public health care system ${ }^{6}$ and the pilot project instituted in rural Haiti, the poorest country in the Western hemisphere?

\section{AFFORDABLE NATIONAL HAART PROGRAMME}

In ongoing discussions surrounding the roll-out of ARVs by the state, cost is often mentioned as one of the 'problems'. In fact, a costing model of a rationed national HAART programme has recently been shown to be affordable within present South African budgetary constraints ${ }^{6}$ and elements of civil society are now demanding increased access to HAART in the publiz health sector. ${ }^{9}$

With 360000 estimated AIDS cases in South Africa" an ART programme will need to be of a similar magnitude to that of the TB treatment programme and will face similar challenges as high levels of adherence to potentially toxic drugs are required for a prolonged period of time. The TB control programme utilises a standard two-scheduled approach to drug therapy, which simplifies the operational implementation necessary for a large national programme.

\section{ART TREATMENT REGISTER}

The national TB register allows performance assessments to be made of individual clinics and ultimately the programme as a whole. Similarly, an ART scheduled approach would simplify training and education of medical personnel and would result in predictable patterns of toxicity and of resistance. A predetermined standardised sequence of drug combinations would also limit the number of drugs to be procured and managed.

There is an urgent need to establish a minimum data set required to allow evaluation and comparison of ARV projects in Africa.

A proposed register documenting entry criteria and recording ARV scheduled therapy would allow an overall audit of programme performance in a similar fashion to that of the TB register. Incorporation of the national ID number in conjunction with national death registration data would allow calculation of the survival of patients entering the programme on an 'intention to treat' basis (Fig. 1).

Comparison of these data with modelled survival of patients determined by baseline characteristics at entry to the programme would allow calculation of life-years gained by the programme. A national ART programme would utilise large quantities of relatively expensive drugs, and the financial burden of poor drug accountability could seriously undermine such a programme. The ARV treatment 

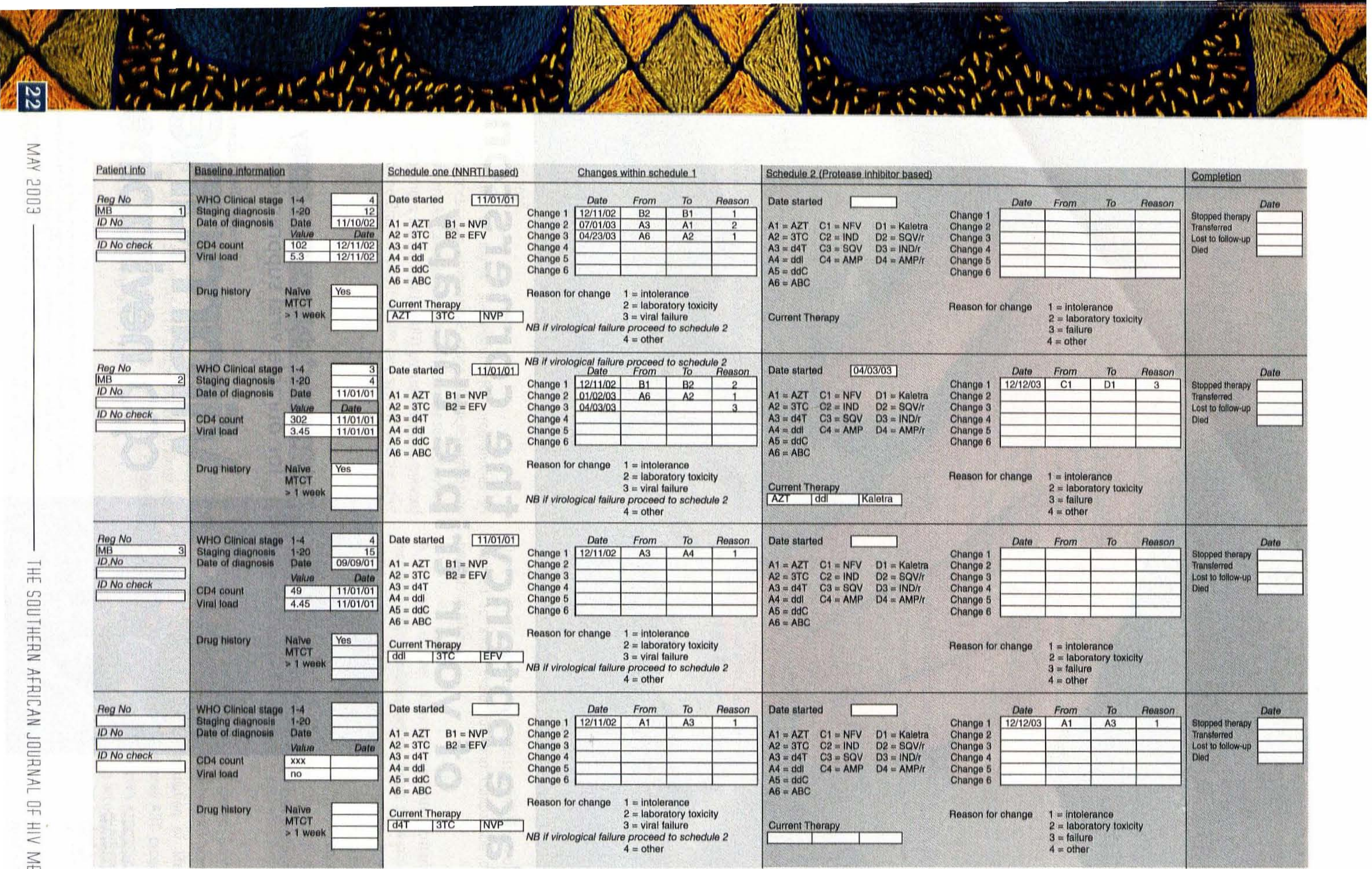

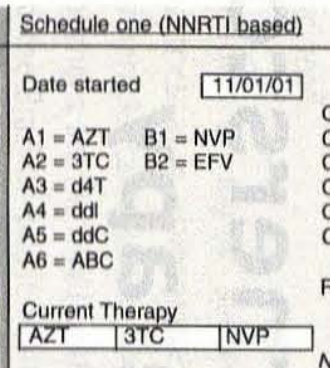

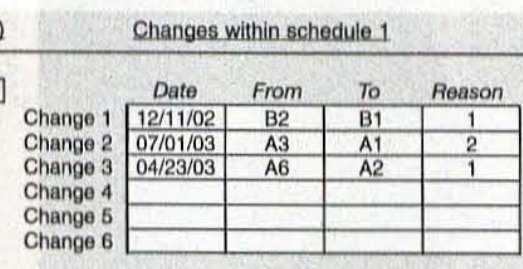

Schedule 2. (Protease inhibitor based)

$A 1=A Z T \quad C 1=N E V \quad D 1=K a l e t r$

$\mathrm{A}_{2}=3 \mathrm{TC} \quad \mathrm{C2}=\mathrm{IND} \quad \mathrm{D} 2=\mathrm{SQV}$

$\begin{array}{lll}A 3=d 4 & C 3=S O V & D 3=I N D / r \\ A 4=d d & C 4=A M P & D 4=A M P / r\end{array}$ $\square$
Change 6 - $\begin{aligned} & A 5=d d C \\ & A B=A B C\end{aligned}$

Aeason for change $\quad 1=$ intolerance

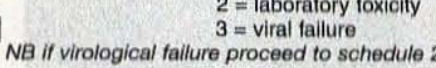
$4=$ other

Current Therapy

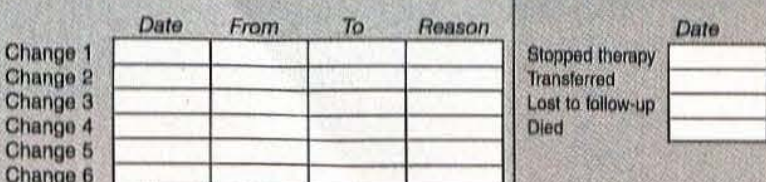

Date started $11 / 01 / 01$ NB If virological fallure proceed to schedule 2
Date From To Feaso

(n)

Reason for change $\quad 1=$ intolerance $2=$ laboratory toxiclity
$3=$ failure $4=$ other

$A 1=A Z T \quad B 1=N V P$

$A 2=3 T C \quad B 2=E F V$

$A 3=d 4 T$

$A 5=d d C$

Change 1 \begin{tabular}{|c|c|c|c|}
\hline $12 / 11 / 02$ & B1 & Bo & Reason \\
\hline 0.102 & 2 \\
\hline
\end{tabular}

Date started $\quad 04 / 03 / 03$

$A 1=A Z T \quad C 1=N F Y \quad D 1=$ Kaletr

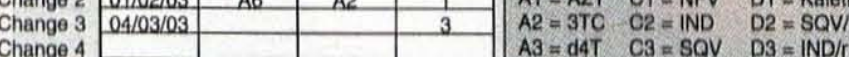

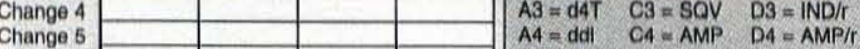
$A B=d a C$
$A G=A B C$

Reason for change $\begin{array}{ll}1=\text { intolerance } \\ 2=\text { laboratory toxicity }\end{array}$ $3=$ viral failure
NB If virological failure proceed to schedule $4=$ other

Current Therapy
\begin{tabular}{|l|l|l|l|}
\hline AZT & dd & |Raletra \\
\hline
\end{tabular}
\begin{tabular}{c} 
Date \\
Change 1 \\
\begin{tabular}{|c|c|c|c|c|}
$12 / 12 / 103$ & From & To & Reason & 3 \\
\hline Stopped therapy
\end{tabular} \\
\hline
\end{tabular} Change 2

Change 3
Change 4
Che

Change 6

Reason for change $\quad 1=$ intolerance $2=$ laboratory toxicity
$3=$ tailure

$4=$ other
Date From To Reason

Date started $\quad 11 / 01 / 01$

Date started $\square$

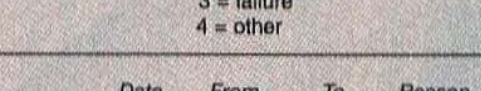

$\begin{array}{lll}A 1=A 2 T & C 1=N F V & D 1=\text { Kaletra } \\ A 2=3 T C & C 2=I N D & D 2=S O V / I\end{array}$

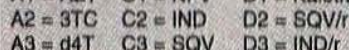
$\begin{array}{ll}A 1=A Z T & B 1=N V P \\ A 2=3 T C & B 2=E F V\end{array}$

$A 3=d 4 T$
$A 4=d d \mid$

$A=d d C$
$A 6=A B C$ \begin{tabular}{l} 
Change 1 \\
Change 2 \\
Change 4 \\
\hline
\end{tabular} Change 4
Change 5
Chang Change 6

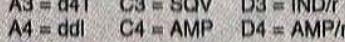

Reason for change $1=$ intolerance

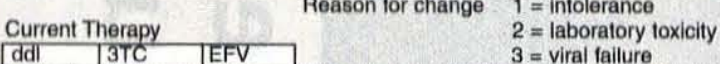
$A 5=d d C$
$A B=A B C$

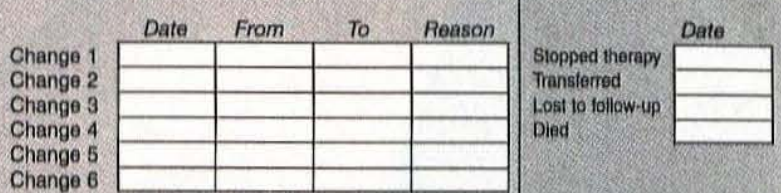
$3=$ viral tailure
NB If virological fallure proceed to schedule 2 $=$ other

Reason for change $\quad 1=$ intolerance $2=$ laboratory toxicity $4=$ other

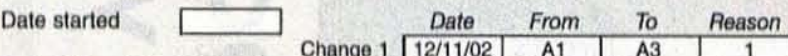
$A 1=A Z T \quad B 1=N V P$ $\begin{array}{ll}A 2=3 T C & B 2=E F V\end{array}$

$A 3=d 4$

$A 4=d d l$
$A 5=d d C$
$A 6=A B C$

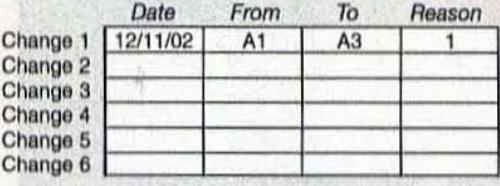
Change 5
Change 6 Reason for change $\quad 1=$ intolerance

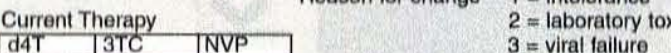
= viral tailure NB if virological failure proceed
\[ 4=\text { other } \] =other to schedule 2

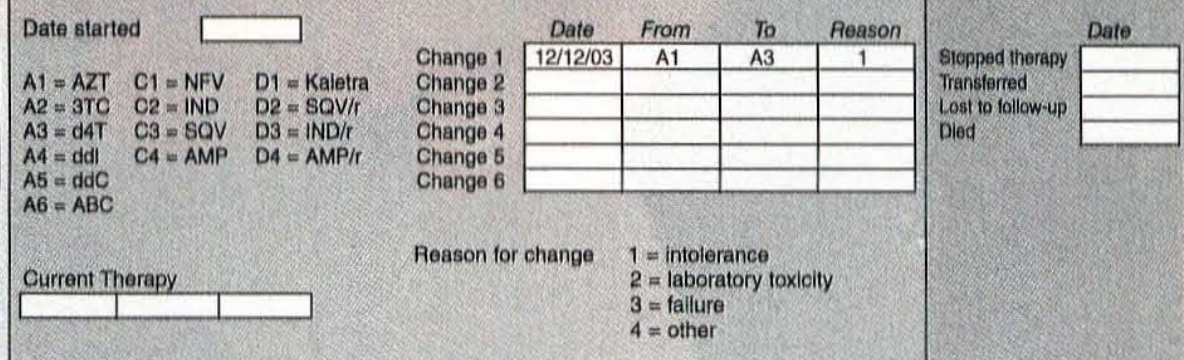


register at any institution could be reconciled against drug purchases by that institution for drug accountability purposes and to identify and avoid 'drug seepage'. Specific questions such as impact of prior exposure to mother-tochild transmission preventive therapy on subsequent response to ART could be answered by analysis of the register database. Blood sampled at the time of failure of the first schedule could also be stored for national viral genotyping surveys, which could give information on patterns of viral resistance, which in turn would allow scientifically based changes in scheduled drug choices.

An ART register would need to be a standardised form that could be in either paper-or web-based formats. As ART will be provided at health care facilities other than TB clinics the administration of the register would need to be the responsibility of organisations such as the national or provincial AIDS directorates.

\section{OUTCOMES}

The major outcomes of a successful ART programme would be a decrease in AIDS morbidity and mortality. While CD4 cell counts, clinical stage and viral load determine prognosis of untreated patients, effective viral suppression by ART is the major determinant of outcome on treatment."

National and international ART guidelines have been developed and published, which give clear initiation criteria and recommended therapy combinations and could be used as a basis for scheduled drug choice. . $^{4.12}$

\section{LESSONS FROM THE TB CONTROL PROGRAMME}

To encourage the correct usage of ART, it has been suggested that the ART programme be closely linked to and managed within the TB control programmes of subSaharan Africa. ${ }^{5}$ ART cannot, however, be isolated from the wider comprehensive approach to HIV and AIDS patient care, including management of the psychosocial and other medical complications, such as prophylaxis and treatment of opportunistic infection..$^{49}$ It would not be practical or prudent to burden the TB control programme with this heavy responsibility. A scheduled ART approach could be a useful method to enable wider, more equitable access to ART within our existing health infrastructure, and an ART register would be a tool to monitor the overall performance of such an expanded access programme. While expanded access to ART should not be the responsibility of the TB clinics, there may be important lessons to be learned from the programmatic methodological approaches of the national TB control programme.

\section{PROTOCOL OUTLINE}

The proposed register would be web-based with password- protected access from registered PCs only. Entry of the individual national identity number would lead to an allocated site registration number, which would be used in all future communications. The proposed format of the register is shown in Fig. 1, and all data entry will be by 'point and click' menus. Baseline data will be entered including age, sex, WHO stage and staging conditions, baseline CD4 count and the initial treatment schedule chosen by the practitioner. Subsequent changes in treatment regimens would be categorised as due to toxicity, drug intolerance or viral failure together with dates of changes. The present drug regimen will be shown in an automatically updated regimen box.

Blood samples for genotyping will be stored at each change of therapy triggered by viral failure. Automatic e-mail requests for patient status will be generated to confirm whether subjects are still actively followed up or lost to follow-up. Funding has been sought to perform genotyperesistant pattern at the time of first failure of the second regimen. It is intended that these data be made available to the clinician for clinical decision-making.

\section{REGISTER OUTPUTS}

The register is intended to act as a pilot audit of current ARV clinical practice and to develop a tool for monitoring increasing widespread access to HAART. The primary aim is to assess the overall prognosis of subjects initiating HAART treatment in South Africa by establishing 'intention to treat' survival. Secondary endpoints include length of time on first non-nucleoside reverse transcriptase inhibitor (NNRTI)-based regimen in clinical practice, time to first virological failure and comparative tolerability of different starting regimens. Initial viral resistance genotype data will be made available for longitudinal population surveillance of circulating pre-treatment resistant mutations. Subsequent genotypic data will reflect viral response to present drug pressure and aid clinicians' therapeutic choices after failure of the protease inhibitor (PI)-based regimen.

\section{PARTICIPATION}

It is envisaged that members of the SA HIV Clinicians Society who are experienced treaters participate in the programme by entering the password-protected Internet site from registered PCs. As indicated above, the entry of the individual national identity number would lead to an allocated site registration number, which would be used in all communications.

Participating medical practitioners would be required to recruit drug-naïve patients and be willing strictly to follow the current HIV Clinicians Society guidelines. The initial regimen would be an NNRTI-based regimen and the 
subsequent or second-line regimen would be Pl-based.

Any interested treaters who would like to participate should e-mail the managing editor of the Southern African Journal of HIV Medicine at Igbekker@cormack.uct.ac.za, expressing the number of patients likely to be treated at their site in the next year.

REFERENCES

Morcroft A, Vella S, Benfield Th et al. Changing mortality across Europe in patients infected with HIV-1. Lancet 1998; 352: 1725-1730.

2. Moore RD, Chaisson RE. Natural history of HIV infection in the era of combination antiretroviral therapy. AIDS 1999; 13: 1933-1942.

3. Palella FJ, Delaney KM, Moorman AC, et al. Declining morbidity and mortality among patients with advanced human immunodeficiency virus infection. $N$ Engl J Med $1998 ; 338: 853-860$

4. World Health Organisation. Scaling Up Antiretroviral Theropy in Resource-Limited
Settings: Guidelines for a Public Health Approach. Geneva: WHO, 2002.

5. Harries AD, Nyangulu DS, Hargreaves NJ, Kaluwa O, Salaniponi FM. Preventing antiretroviral anarchy in sub-Saharan Africa. Loncet 2001; 358: 410-414

6. Levi GC, Vitoria MA. Fighting against AIDS: The Brazilian experience. AIDS 2002; 16 : 2373-2383.

7. Farmer $P$, Leandre F, Mukheriee 15 , et ol. Community-based approaches to HV treatment in resource-poor settings. Lancet 2001; 358: 404-409.

8. Boulle A, Kenyon C, Skordis J, Wood R. Rationing HAART Part I: An exploration of the costs of a limited public sector antiretroviral treatment programme in South Africa. SAfr Med \2002; 92: 811-817.

9. Bredell Consensus Statement on the Imperative to Expand Access to Antiretroviral Medicines for Adults and Children with HIV/AIDS in South Africa. November 2001 Notional Treatment Congress Resource Document Number 12. Cape Town: Treatment Action Campaign

10. Report on the global HIV/AIDS epidemic. Joint United Nations Programme on HIVIAIDS (UNAIDS). Geneva: UNAIDS, July 2002

11. Egger $M$, May $M$, Chene $G$, et al. Prognosis of HIV-1-infected patients starting highly active antiretroviral therapy: a collaborative analysis of prospective studies Lancet 2002; 360: 119-129.

12. Southern African HIV Clinicians Society. Clinical Guidelines: Antiretroviral Therapy in Adults. June 2002 version. Southern African Journal of HIV Medicine 2002; July (Issue 8): 22-29.

\title{
GUIDELINES
}

\section{INFANT HIV DIAGNOSTIC GUIDELINES TO FACILITATE ADOPTION}

\author{
Gayle G Sherman, $M B B C h, D C H$ (SA), DTMEH, MMed (Haem) \\ Department of Molecular Medicine and Haematology, fohannesburg Hospital, National Health Laboratory Service and University of the \\ Witwatersrand, fohannesburg
}

South Africa is currently estimated to have 300000 HIVIAIDS orphans, and the figure is likely to increase to 2 million by 2015.' Facilitating adoption of children affected by HIV provides a highly effective strategy for addressing the HIVIAIDS orphan crisis, albeit on a very small scale. The legal and ethical issues surrounding HIV testing of abandoned children for the purposes of adoption are not addressed here.
The qualitative HIV polymerase chain reaction (PCR) test is highly specific for HIV infection, but sensitivity varies with the age of the infant. ${ }^{2}$ The PCR identifies approximately $50 \%$ of infected infants at or just after birth and $>95 \%$ at $3-6$ months of age..$^{23}$ More recent evidence suggests that HIV PCR tests performed at $\geq 1$ month of age have a sensitivity of $\geq 95 \%$ and specificity of $>99 \%{ }^{4}$ The Roche Amplicor Kit (Roche Molecular Systems, Somerville, NJ)

These guidelines were contributed to and are endorsed by:

Dr Ashraf H Coovadia

Department of Paediatrics, Coronation Hospital, and University of the Witwatersrand

Dr Mark F Cotton

Paediatric Infectious Disease Unit, Tygerberg Children's Hospital, University of Stellenbosch

Dr Glenda E Gray

Perinatal HIV Research Unit, Chris Hani-Baragwanath Hospital and University of the Witwatersrand

Professor Gregory D Hussey

School of Child and Adolescent Health, University of Cape Town

Dr Leon J Levin

Paediatrician in private practice

Dr Tammy M Meyers

Department of Paediatrics, Chris Hani-Baragwanath Hospital and University of the Witwatersrand

Professor Lynn Morris

AIDS Unit, National Institute for Communicable Diseases and University of the Witwatersrand

Dr Adrian J Puren

National Institute for Communicable Diseases and University of the Witwatersrand

Dr Wendy S Stevens

Department of Molecular Medicine and Haematology, National Health Laboratory Service and University of the Witwatersrand

Dr Lynne M Webber

Department of Medical Virology, University of Pretoria 